\title{
A Strategy to Improve The Usage of ICT in The Kingdom of Saudi Arabia Primary School
}

\author{
Gafar Almalki \\ (School of Computer Science, Engineering and \\ Mathematics): Flinders University \\ Adelaide, Australia
}

\author{
Neville Williams \\ (School of Computer Science, Engineering and \\ Mathematics): Flinders University \\ Adelaide, Australia
}

\begin{abstract}
Integration of ICT in education is a complex idea that requires practical interpretation to get significant outcomes. As a developing country, the Kingdom of Saudi Arabia (the KSA) does not have a proper technological infrastructure as developed countries. Efficient strategies are vital in improving the application of ICT in the KSA's primary schools effectively. Improving the usage of ICT in the KSA primary schools achievement entails integrating ICT into classroom. However, some barriers that prevent a successful ICT implementation in the primary school are still present. This paper proposes several strategies to trounce the challenges. Several recommendations for ICT integration in primary school applicable in the case of the KSA are also necessary. These strategies are executable at school and national scale.
\end{abstract}

Keywords- ICT; primary school; barrier; strategy.

\section{INTRODUCTION}

Information and communication technologies (ICT) are indispensable tools for any organization to stay competitive and play their role efficiently and effectively. A significance gain is achievable by organizations, which adopt and implement ICT successfully [1]. In the education sector, ICT is also a potential tool to deliver high quality education and prepare students for the information era [2]. When computers, as part of ICT, integrate into the educational system, several expectations will arise such as a reduction of teachers' efforts to deliver knowledge, achievement of better visualization, and encouragement of students' motivation [Marcuse-Hass and Kromenholtz cited in 3]. However, integration of ICT in education is a complex idea, which practical interpretation interpreted is a significant outcome [4].

As other developing countries, the Kingdom of Saudi Arabia (the KSA) has no proper technological infrastructures like developed countries. Therefore, efficient strategies are crucial to improve the usage of ICT in the KSA primary schools effectively. Integrating ICT into classroom improves the usage of technology in the KSA primary schools. However, some barriers, which prevent a successful ICT implementation in the primary schools, still prevail. An analysis to understand how teachers and students utilize ICT and impacts of teaching and learning process in the classrooms is extremely valuable to construction of strategies to overcome the problems. An intensive review of the ICT usage in the schools is essential. It aims at identifying and categorizing useful strategies, which are appropriate and applicable in the KSA.

The aim of the study is to develop a set of strategies to improve the usage of information and communication technologies (ICT) in the Kingdom of Saudi Arabia primary school. The categories of the usage of ICT are 'supportive ICT use' and 'classroom ICT use'. Supportive ICT use refers to the application of ICT for practical, educational support such as school administration, teaching management and administration and preparation of worksheets for student assignment. Classroom ICT use is the implementation of ICT in teaching and learning process in the classroom and science labs such as use of computers for demonstration and visualization, drilling, and practice activities [Tondeur et al. cited in 5].

\section{REVIEW TECHNOLOGICAL USAGES IN PRIMARY SCHOOL}

\section{A. Types of Educational Computer Use}

Most of The ICT research studies explore the conditions that can sustain its integration into schools. In this context, many researchers present frameworks or models demonstrating conditions that can have an influence on ICT integration into teaching and learning methods. These frameworks are mostly on two basic methods: 'qualitative research methods' [for example, 6] and 'quantitative research methods' [for instance, 7]. All the aforementioned frameworks have one thing in common that ICT integration is described from a holistic point of view under the influence of conditions situated on different levels (pupils, teachers, schools, and policy makers) [7].

Based on an empirical study involving a large segment of teachers, Tondeur et al. [cited in 5] describes two main categories of ICT use by teachers: supportive ICT use and classroom ICT use. Supportive ICT refers to the use of ICT for practical as well as organizational teaching responsibilities such as, student administration, teaching management and administration, preparing worksheets, developing evaluation activities presuming students' learning progress in a given situation.

The next category, 'classroom ICT use' focuses on supporting and heightening the actual teaching and learning processes, for instance, how computers are applicable in 
demonstration purposes, drilling and practice activities. It also entails representation of intricate knowledge elements, deliberations, cooperation, and project work. Furthermore, Wozneyet et al. [cited in 5] finds that supportive use of ICT is the most decisive factor to appraise the classroom use of ICT.

\section{B. Characteristics of ICT Usage}

Tondeu, Valcke, \& van Braak [8] explore the individual characteristics of teachers and school environment that relates to various types of computer usage in primary schools. There was a survey in Flanders primary schools whereby administration of questionnaires relates to (ICT) coordinators from the same schools to collect auxiliary information in accordance with the cultural and contextual school characteristics.

Strenuous efforts existed, in the quest to determine the effects of teachers and relative school features in the investigation. As the study reveals that cultural school characteristics, constituting the schools' readiness to change as well as the availability of an ICT based school policy plan, links to the use of computers as an educational instrument. The cultural school also links to the implementation of ICT with consideration to the fundamental computer skills. On the contrary, no cultural school characteristic is likely to have links independently, with the use of computers as an information instrument. A multidimensional approach can bring a more conductive and meaningful insight to the characteristics affecting the use of computers.

\section{ANALYSIS}

The Ministry of Education, the Ministry of Higher Education and the General Organization for Technical Education and Vocational Training have joint responsibility to manage education system in the KSA. Kindergarten is for children aged 3-5 years, but it is not a condition for enrollment in primary educations.

The first grade of primary education is for children aged six years. They must pass the final examination at the end of Grade 6 and obtain the Elementary Education Certificate in order to move to intermediate education. The students study at intermediate education for three years. They also must study for three years at secondary education, which acts as the final stage of general education. Students can go to higher education subsequent to going through secondary education [9]. Table 1 shows the number of students and teachers at each level in 2007 [10].

Number of Students and Teachers in 2007

\begin{tabular}{lllll}
\hline \multirow{2}{*}{$\begin{array}{l}\text { Lducation } \\
\text { Level }\end{array}$} & \multicolumn{2}{c}{ Students } & \multicolumn{2}{c}{ Teachers } \\
\cline { 2 - 5 } & Male & Female & Male & Female \\
\hline Primary & $1,255,117$ & $1,187,365$ & 107,227 & 110,328 \\
Intermediate & 609,300 & 535,248 & 54,034 & 54,031 \\
Secondary & 541,849 & 471,225 & 41,108 & 46,715 \\
\hline
\end{tabular}

ICT have a potential to change the ways of teaching. However, to achieve satisfactory results, some consideration on barriers that hinder the implementation gives the best way to start. Balanskat, Blamire and Kefala [cited in 11] state that although teachers acknowledge the importance of ICT to improve the learning process, some problems continue to arise during the process of adopting these technologies. This section describes several problems on the implementation of ICT in several countries, which may reflect in the KSA.

An undertaken analysis represents an understanding of how teachers and students utilize ICT and what the impacts for teaching and learning process in the classrooms. Researchers have used several categories to classify barriers relating to implementation of ICT on school. Hew \& Brush [6] identified the barriers into several groups, namely: (a) resources, (b) institution, (c) subject culture, (d) attitudes and beliefs, (e) knowledge and skills, and (f) assessment. Bingimlas [11] divided the barriers into (a) teacher level and (b) school level. Mohamed, Abuzaid \& Benladen [12] regarded the barriers as cultural and technical constraints. This analysis concentrates on teacher factor, school/institution factor and extrinsic factor.

\section{A. Teacher Factor}

Teacher-related serves as the most significant predictor for technology adoption. Teachers are critical key to successful adoption of ICT while teachers' professional development needs to focus on technology skills and support for pedagogical change to embed ICT' [13]. Teachers should be at the center of ICT adoption projects. Marcinkiewicz [c,ted in 5] stressed that the full integration of ICT in education will remain a remote target to achieve, unless the gap between teachers perceived impediments and the use of computers occurs caution. The three categories related to the teachers are:

\section{1) Lack of teacher confidence}

Several references reported that inadequacy in teachers' poise prevents them to use ICT on class. Becta [cited in 11] found that teachers were afraid to use ICT in the classroom as they feel having limited knowledge in the area of ICT. Lack of confidence will also reduce teachers' enthusiasm in using ICT as a useful tool in the teaching process [11]. A study conducted in 2005 by Jamieson-Proctor et al. [14] indicates that $73 \%$ of female teacher in Queensland State, are less confident to use ICT for teaching and learning process in classrooms. This number was significantly greater than their male counterparts were.

\section{2) Lack of teacher competence}

Inadequate teacher competence is a barrier, which influences negatively teachers' confidence. William et. al. [cited in 6] found that $10 \%$ more of elementary school teachers in Scottish school have not enough skills on databases and spreadsheet. In Australia, Newhouse [cited in 11] found that many teachers were not enthusiastic to integrate ICT with teaching activities since they do not have enough knowledge and skill about this technology. In United States, Snoeyink and Ertmer [6] also found that lack of computer skill was becoming a barrier for teachers to integrate ICT into the teaching process on the classrooms. 
In Malaysia, lack of teacher expertise on ICT is the main constraint of promoting ICT in schools [15]. A study by Cavas et al. [16] in Turkey found that Turkish primary science teachers' positive approach to ICT, received impact from their computer ownership at home and their computer experience.

\section{3) Negative attitudes}

Teachers' participation is significant since it influences the success of ICT implementation in the schools [7]. Schoepp [cited in 11] states that although some teachers have enough knowledge and skill on ICT, they did not intend to use ICT because of the belief that there are not appropriate rewards for using it. Furthermore, some teachers believed that there is no relationship between ICT and an effective teaching [6]. For example, a study in Australia revealed that most of the teachers believed a better learning could not occur by using computer [Newhouse cited in 6]. In addition, JamiesonProctor et al. [14] found that there is significant resistance from teachers in Queensland State to use ICT as required by the curriculum.

The teachers who have an obsession and sheer commitment for boosting their learning processes can more likely incorporate technology in their teaching. This view is also consistent with findings by Sang et al. [5] that amongst variables of the internal teachers, ICT incentive appears to be the ICT classroom exploit strongest predictor. In addition, attitudes of teachers towards the application of ICT in education relates to ICT motivation as part of the predictor of ICT classroom use.

\section{B. School/Institution Factor}

\section{1) Lack of time}

Using ICT on the classrooms needs a reliable preparation, which may consume much time. Teachers need many hours to search suitable resources on the Web, prepare photos and videos for multimedia presentation. If the schools do not reduce teachers' teaching time as compensation, it is difficult to expect the teachers to use ICT on their classroom [6]. Furthermore, availability of computers in laboratories does not guarantee the teachers to access it if they should compete with the other teachers for laboratory time [Zhao, Pugh, Sheldon, and Byers cited in 6]. In Saudi Arabia, Al-Alwani [cited in 11] found that teachers do not want to use ICT as they have a busy schedule.

\section{2) Lack of efficient training}

Lack of teacher competence and skill is the main barrier of ICT classroom integration. A good training for teacher may be a solution for the problem. Therefore, lack of effective training for the teacher is a significant barrier for the implementation of ICT on classroom [19]. Gomes [cited in 11] states that insufficient training in digital literacy, pedagogic and didactic training becomes barriers for teachers in applying ICT in the classrooms.

\section{3) Lack of local technical support}

Neyland [18] states that provision of ICT and technical support are first order factors affecting technology integration'. It is common that the teachers face technical problem when working in technology-integrated-classroom. On this classroom, there are various kinds of technological resources such as computers, LCD projector, printers, CDROMs, whiteboard and other multimedia device.

It is hard to encourage teachers to use ICT without immediate support from skilled staffs. This is when the teachers have difficulties in operating the technological resources [Lim et al. cited in 6]. Indeed, short of technical assistance is significant constraints for using ICT [Pelgrum cited in 11]. In New Zealand, a study by Education Review Office of New Zealand revealed that technical support was a significant factor for successful use of schools' e-learning packages [18]. In Saudi Arabia, teachers were not in agreement with the idea of applying ICT without technical support [Almohaissin cited in 11].

\section{4) Leadership barrier}

A good example from the leaders (school principal) is a significant factor for the successful integration of ICT in school. Stuart et al. [20] state that the leadership behaviors of senior management contribute pivotally in determining the success or failure of an ICT implementation'. Fox and Henri [cited in 6] reported that most of the teachers in Hong Kong had no interest in using ICT in the classroom. This results from the feeling support deficiency from the principal who did not understand ICT. In Victoria, Australia, the successful implementation of ICT into the curriculum requires the commitment of the school leaders to arrange suitable training for the teachers [21].

\section{Extrinsic Factor}

\section{1) Local culture}

One of the considerable advantages of using ICT is the possibility to deliver information over the internet, which performs e learning. However, unsuccessful adoption of e learning in developing countries resulted from direct copy from developed countries that have significantly different cultures [Wurm 2008 cited in 12].

A few more studies have explored how these factors influence in a direct and/or indirect way the levels of ICT integration in classrooms. Although the question about ICT integration in education has global significance, yet the cultural variables have, should also be part of the consideration. For instance, cultural differences identified through comparing the Chinese and Flemish teacher perspectives in the use of ICT in teaching and learning methodologies [Zhu et al. cited in 5].

According to their findings, Chinese teachers, in particular, express more doubts about the constructivist principles underlying many ICT applications inclusive but not limited to collaboration, independent learning, and self-directed learning. These differences are noticeable with the ideas of Chinese teachers as compared to the Flemish teachers concerning teacher-student and student-student interactions. This links to disparity in the cultural dimensions of both societies e.g., power distance, collaboration, and competition significantly. Chinese teachers nevertheless put a larger emphasis on those nuances. 
Implementation of ICT continues through the provision of access to the Internet. There are many negative views about contents of the Internet such as extreme political beliefs, pornography, and strange religions [Postrel cited in 22]. Although all of these factors may be not considered ethically abhorrent' in some western societies, it cannot be accepted in the KSA culture which bases on the Islamic religion [22]. Indeed, after a long national debate about the social risks of the Internet, the internet introduction in the KSA in 1999 was to support e-learning [Wurm 2008 cited in 12]. Modification of the example strategies from other countries is necessary for ICT adoption in the KSA.

\section{2) Lack of funding support}

Integrating ICT into the school program requires a high cost for the supply and maintenance of this technology [23]. Sufficient funds are one of the keys to successful implementation of ICT in the schools [15]. Without sufficient funds, the schools cannot provide software and hardware such as computers and its peripherals. Hew \& Brush [6] state that without adequacy of these technological resources, it was difficult to encourage teachers to use ICT in the classrooms. Indeed, a sufficient fund is one of an important factor to ensure sustainability ICT integration in the primary school.

\section{3) Lack of appropriate planning}

A successful ICT integration requires a good planning. Technology alone was not sufficient to integrate ICT in the classrooms. A comprehensive plan for introducing ICT in the society was also required [Mool cited in 23]. Somekh [13] states that 'the complexities of educational innovations require a holistic strategy capable of building change in social practices informed by the practical power of theoretical knowledge'. A good comprehensive planning is essential to solve simultaneously problems such as lack of appropriate planning, lack of funding support, coping different local culture and lack of effective training.

\section{DISCUSSION AND INITIATIVES}

Various references propose a varied solution for the implementation of ICT in schools. This section examines solutions adaptable to KSA.

\section{A. Personal Development for Teachers}

Some recent researches reveal that irrespective of teachers' earnest inclination, profound interest in knowing the potential of ICT, their practical use of ICT is comparatively low, and it generally focuses on a limited range of applications. On the other hand, another international survey on teachers' perceived impediments in using ICT reveals three main factors i.e. their lack of resources, their lack of knowledge and skillfulness and instructive complexities to incorporate technology in instruction. However, the competency and compatibility of teachers' self-assurance in their expertise, is a key to understand their eagerness to integrate technology in their instruction. Zhao and Cziko [cited in 25] explored three conditions that can help motivate teachers in using ICT to carry out their pedagogical responsibilities:
(1) Teachers should have faith that the use of technology would enhance the effectiveness of their goals, which is unachievable through ordinary means,

(2) They should also believe that the use of technology would not hamper the other high-level goals they want to accomplish, and

(3) They should believe that they have full command on available resources and have enough potential for effectively utilizing ICT. Cox [cited in 26] states that a positive perception of students and teachers to the value of ICT will encourage them to use ICT. Therefore, understanding the teachers' perception toward ICT will help the decision maker (government or school principal) to make plans on how the teachers will adopt ICT in their teaching activities.

Professional development for teachers was considered as a critical factor in the successful integration of ICT in schools [Way \& Webb cited in 18]. Teachers should have 'technologysupported-pedagogy knowledge' which is required when they plan to integrate ICT in classrooms [Hughes cited in 6]. By this knowledge, teachers may ask students to write their assignments in a word processor document rather than submitting a hand-written paper. The teachers may also give art assignments drawn on graphic software or a $2 \mathrm{D} / 3 \mathrm{D}$ modeling software.

Training teachers enable teaching in 'student-centered way' and develop 'individual learning program' for their students. They also encourage the students to work independently on their own computer [23]. A school in Sidney conducted a regular workshop to increase teacher confidence in ICT. The workshop involved local experts and consultants to ensure a sustainability [23]. Furthermore, Jones [cited in 26] states that the barriers that hamper the teacher from using ICT can be eliminated through two ways, namely, individual level enablers and whole school level enablers. At individual level, the teachers have full access to personal PCs or laptops with good quality hardware and software, access to good educational resources, and appropriate training. At whole school level, adequate technical support, effective timetabling, support from senior staff or principal and adequate equipment, such as whiteboards in classroom are key factors.

To sum up, basic and general ICT training for all primary school teachers is required and offered at the national level by the government of the KSA. More advanced and specific ICT training should be at the school level and with its subjects determined by each school requirements.

\section{B. Training for Students}

Availability of ICT resources will not be useful if the students have no skill to use it in their learning process. Therefore, the school should provide basic training for the students. In Malaysia, there was program called 'Pintar', which delivered basic ICT training for students from lowincome families. The training had the aim of increasing the motivation to learn in students [15]. Indeed, as training for teachers is given, suitable ICT training for students is also required. 


\section{Institution/School Support}

Support from institution/school is required to perform 'supportive environment' which include encouragement to use ICT, training, and in providing technical support staff [28]. All ICT components, hardware and software, should be well maintained, with technical support available when teachers have difficulties to operate it [23]. Hiring special staff, that has the responsibility to support ICT implementation in the primary schools, may be a good solution.

A well planned timetable may provide the teachers more time to prepare teaching material which use ICT [28]. By reducing teachers' workload, they will have more time for developing learning program with their colleagues, trying new method to teach in ICT environment, and thinking about better pedagogical practices [23]. Schools should also facilitate work groups, which enable the teachers to work together in producing learning materials. This effort will save teachers time, while increase their productivity.

As a leader, the schools principals' commitment to improve the usage of ICT will support the successful integration of ICT in the school. This support can be in the form of improvement of curriculum and establishing technology committee, encouraging teachers to improve their technological skills, providing appropriate resources and continuous monitoring. The technology committee main task is the development of plans and strategies to ensure that ICT integration will work well [23]. Furthermore, from questionnaires to teachers on online learning tool integration in schools, Neyland [18] concluded that 'local leadership, including the level of school support and commitment to innovation, was seen to be more important than broader systemic level strategies'.

The effort by schools in integrating ICT in science laboratories will assist students in getting intriguing visualizations of nature proceedings. This effort will be inspirational to students in familiarizing with ICT alongside developing their learning capabilities [29].

\section{Community and Government Support}

When schools have adequate finances, ICT access sustainability will be a guarantee. Government financing is a top prerequisite for the provision of appropriate software and hardware to the schools. Support from finances raised by the association of parents allows for the continuity and access achievement in the access of the ICT[28].

Involving commercial ventures is also a significant step. In India, there was software provision by Pearson Education that combined the ELearning tools, administration tools, management of homework tools, and management of teacher's resources. There has been a successful running of pilot projects in 125 schools. The tools possibly will assist the schools with the implementation of ICT along with saving their worthy time[30].

1) Example of State / National Scale Project in Developed Countries

Technology in itself was not satisfactory for ICT integration in classrooms. A detailed plan for the introduction of ICT in the social order was elementary [Mool cited in 23]. The government ought to develop an integrated plan and for an ICT implementation structure on a national scope.

In Australia, the NSW government undertook a 'Computer in School Plan' project, which involved updating computer hardware and software regularly, providing computers for use, and developing an enhancement curriculum [23]. In UK, the government launched City Learning Centers (CLCs) to integrate ICT into schools. This program has increased usage of ICT in lesson planning and teaching programs as the teachers have increased access to ICT.

There is a provision of various trainings on the computer and package software operations. As a result, the teachers became increasingly confident in operating computers in during their lessons [31]. Furthermore, on January 2002, the Welsh Assembly Government in UK incurred £9.9 million from grants to provide all the primary schools with interactive whiteboards (IWB), computers, and projectors. The IWB displays projected images and permits users to have power over the connected PC through a touch on the board. Even though, other teachers require convincing regarding the usefulness of IWBs, most believe the tool is extremely significant for the future of teaching [Kennewell \& Morgan cited in 17].

In South Korea, the integration of ICT in education is a significant factor necessary for the attainment of a rapid economic growth and development. Since 1970, the government of South Korea has been providing considerable finances towards the integration of ICT in education. The use of ICT in education, prepared the South Korea population to a quick adaption of science and technology in the labor market [Kim cited in 32]. In 1990, the government of South Korea introduced an eight-year plan of offering trainings to teachers on the use of ICT. The plan was part of the government's master plan for education. The training was an immense success and became a basic pillar for the integration of ICT in the education system of South Korea [32].

\section{2) Example State / National Scale Project in Developing}

\section{Countries}

Chile had Enlaces as its national program, which was useful for the implementation of ICT in schools alongside its integration in the curriculum. The objective of the program was to advance the quality of national education through the provision of a suitable ICT infrastructure, teachers' training, and implementation of digital resources. The project was a massive success as it was sustainable for both the rural and urban areas [33].

To reduce the risk of ICT-marginalization in the Arab World, Dutta et al. [34] suggests, 'devise a clear and comprehensive ICT development plan, supported by the highest political constituencies' and 'incorporate ICT skills and knowledge into the educational system'. Egypt acts as the first example in the Arab World. Egypt's Ministry of Communications and Information Technology centers its attention and energy towards expansion, utilization of the human resources required for the development of telecommunications, and IT sectors. 
The government introduced an exclusive professional training program that will produce 5,000-trained professionals in IT per-annum. The ministry also plans to open a National Information Technology Institute (NITI) from which it will endeavor to patronize all the training programs necessary for the progression of IT skills across the country. The ministry plans to set up technical universities in the country and encourage the sending of young professionals abroad for further training. The ministry also considers taking the necessary measures needed for the advancement of the ICT based curriculum in Egypt [34].

Likewise, in Kuwait, the Ministry of Education recently launched a provision plan for broadband internet access to about 300 government schools through the issuance of tenders to large companies. The companies are to install basic infrastructures and connection facilities among many others. There is a complete involvement of the private sector in the implementation process, and expansion of the governmental policies towards ICT. This is through the provision of several discounts and concessions to private schools by decreasing the monthly internet charges and leasing of connections to the American and English schools in Kuwait [34]. In the U.A.E., the Ministry of Education, and Youth in collaboration with some foreign donors launched the project of Smart Schools with the purpose of encouraging and enhancing internet usage in schools. The mega project is inclusive of numerous incentives such as free internet installation in the private, government schools, and a discounted usage fees. There are numerous school subscriptions in the U.A.E. to the services[34].

\section{E. Solving Cultural Problem}

Unsuccessful adoption of ICT strategies could be due to direct borrowing from the developed countries that have different cultures with the KSA. For example, a successful implementation of the ICT plan requires continuous provision of internet access. In avoiding cultural conflicts regarding internet access, Sait et al. [22] suggests that the government should have a policy/legislation that will control and standardize the suitable contents. The government of the KSA employs several efforts towards the blocking of websites, which provide unacceptable content in the KSA such as pornographic materials, online gambling and dating. The use of central proxy server(software and hardware system) proved effective and did not cause significant delay for the users [AlFuraih cited in 22].

Education in the KSA applies a gender-segregation policy which prohibits contact among men and women students [12]. Therefore, ICT execution to sustain e-learning should be modified. Mohamed et al. [12] proposed a customized elearning system which limited communication among students from different gender. Only learners and tutors could interact.

Using ICT in the classes passes as adopting Western culture by most of the teachers in the KSA [26]. Therefore, Oyaid (2009) suggested that teachers should ensure that using ICT is compatible with their values, faith, and beliefs. Moreover, acquiring this new technology will make them better teachers as well as a better Muslims. Indeed, this effort may change teachers' negative attitude regarding ICT integration in classrooms into positive attitude.

\section{F. Recommendation for Implementation in the KSA}

The researchers proposed the implementation of several recommendations in the KSA based on several strategies that other countries have adopted:

\section{1) Create a Suitable ICT Infrastructure Environment}

An ICT system consists of hardware, software, people who use them and communications technology such as the Internet. Increasing the usage of ICT in the KSA primary schools is achievable by integrating ICT into the classrooms. Typical ICT projects involve upgrades of equipment (hardware and software) or new installations of the network. However, purchasing complete equipments to support ICT integration require a huge amount of money. Therefore, an integrated planning to improve ICT infrastructure within a medium-term period ( 3 to 5 years) at each primary school is important. The infrastructure can enhance internet access in schools and facilitate e-learning. Moreover, part of the fund should facilitate construction of ICT labs in schools. This effort will help students to get an interesting visualization of the nature process and encourage them to be familiar with ICT and develop their learning skill.

\section{2) Training for Ministry of Education Staff}

The Ministry of Education should develop, manage and control the project of ICT integration in schools. Therefore, the ministry should have competence staff in this area to integrate sustainability concepts and policies into ICT planning, and design projects. The Ministry should also carry out intensive ICT trainings for its staff.

3) Developing ICT Training Program for Teachers in Schools

The ICT trainings should form part of teacher career development. The training materials include 'technologysupported pedagogy knowledge' that is required when they plan to integrate ICT in the classrooms. By this training, the teachers will increase their confidence with ICT and enhance their ability to teach in a 'student-centered way' and developing 'individual learning program' for their students. Specific ICT training for teachers is also required. The school requirements determine the subjects that the teacher will undertake during training.

\section{CONCLUSION}

This study found several barriers of the implementation of ICT in schools. These barriers are in three categories; teacher factor, school/institution factor and extrinsic factor. Several strategies for ICT integration in primary school, which the KSA may adopt, are proposed. At national scale, integrating ICT with the curriculum extends to introducing some subjects related with ICT to the primary schools. The government should come up with integrated planning to improve ICT infrastructure at each primary school.

The ministry should launch basic ICT trainings as part of teacher career development, with materials such as 'technology-supported-pedagogy knowledge', which is required when they plan to integrate ICT in the classrooms. 
Trainings for school principals are also required to improve leadership capability and their commitment to successful integration ICT in the school. Finally, the government may support research to develop a low cost interactive whiteboard that is crucial to improve students' learning abilities and encourage them to participate in the learning process in the classroom.

At institution/school scale, the schools should provide specific ICT trainings for teachers with school requirements determining what subjects to take. Hiring staff for ICT technical support will enable a 'supportive environment', which encourages teachers to use ICT and ensure all of ICT components, hardware and software, are well maintained. Facilitating discussion groups is important as a medium of sharing ideas among teachers about integrating ICT into classes. Creating a good timetable and reducing teachers' workload may provide the teachers more time to prepare teaching materials which uses ICT, developing learning program with colleagues, trying new methods to teach in ICT environment, and thinking about better pedagogical practices. Finally, integrating ICT into science labs will help students to get an interesting visualization of the nature process and encourage them to be familiar with ICT and develop their learning skill.

Quantitative and qualitative studies to evaluate the effectiveness of each strategy are important. Examples of these studies are:

- A study to evaluate suitable ICT training methods for teachers, school principals and Ministry of Education staffs, which the Ministry of Education can implement in the KSA. The training should also encourage teachers to use ICT and become open minded to new technologies.

- There should be a study to produce appropriate learning materials based on ICT, which suits the culture in Saudi Arabia.

- $\quad$ There should be a study to produce an appropriate government policy facilitating quicker ICT in the KSA.

- There should be a study to develop curriculum, which involves ICT as an important part. The syllabuses should include ICT in the course.

- There should be a study to develop software in Arabic language as part of ICT integration in the classrooms. The software also could also support science labs.

The results of the studies are useful in developing more comprehensive and efficient framework for ICT integration in primary schools in the KSA.

\section{REFERENCES}

[1] S.S. Al-Gahtani, "Computer Technology Adoption in Saudi Arabia: Correlates of Perceived Innovation Attributes," Information Technology for Development, vol. 10, pp. 57-69, 2003.

[2] A. Abdulkafi, "Teachers' Attitudes toward Information and Communication Technologies: The Case of Syrian Efl Teachers," Computers \&amp; Education, vol. 47, no. 4, pp. 373-398, 2006.

[3] S. Romi and H. Zoabi, "The Influence of Computer Technology Learning Program on Attitudes toward Computers and Self-Esteem among Arab
Dropout Youth," Educational Media International, vol. 40, no. 3-4, pp. 259-268, 2003.

[4] M. Robertson, I. Webb, and A. Fluck, "Seven Steps to Ict Integration". 2007, ACER Press: Camberwell, Vic.

[5] G. Sang, M. Valcke, J. van Braak, J. Tondeur, and C. Zhu, "Predicting Ict Integration into Classroom Teaching in Chinese Primary Schools: Exploring the Complex Interplay of Teacher-Related Variables," Journal of Computer Assisted Learning, vol. 27, no. 2, pp. 160-172, 2011.

[6] K.F. Hew and T. Brush, "Integrating Technology into K-12 Teaching and Learning: Current Knowledge Gaps and Recommendations for Future Research," Educational Technology Research and Development, vol. 55, pp. 223-252, 2007.

[7] R. Vanderlinde, S. Dexter, and J. van-Braak, "School-Based Ict Policy Plans in Primary Education: Elements, Typologies and Underlying Processes," British Journal of Educational Technology, vol. 42, no. 3, pp. $1-15,2011$

[8] J. Tondeur, M. Valcke, and J. van Braak, "A Multidimensional Approach to Determinants of Computer Use in Primary Education: Teacher and School Characteristics," Journal of Computer Assisted Learning, vol. 24, pp. 494-506, 2008.

[9] UNESCO IBE (2007) Saudi Arabia. World Data on Education.

[10] [10] Kingdom of Saudi Arabia: Ministry of Economics and Planning (2008) Achievement of the Development Plans Facts and Figures Twenty-Fifth Issue 1390-1429h 1970-2008g.

[11] K.A. Bingimlas, "Barriers to the Successful Integration of Ict in Teaching and Learning Environments: A Review of the Literature," Eurasia Journal of Mathematics, Science and Technology Education, vol. 5, no. 3, pp. 235-245, 2009.

[12] A.H. Mohamed, R.A.S. Abuzaid, and R.M. Benladen, "Opportunities and Challenges of the Knowledge Management Approach to E-Learning: A Case Study in Al-Bayan Model School for Girls, Kingdom of Saudi Arabia," The Electronic Journal on Information Systems in Developing Countries, vol. 35, no. 4, pp. 1-11, 2008.

[13] B. Somekh, "Factors Affecting Teachers' Pedagogical Adoption of Ict," in International Handbook of Information Technology in Primary and Secondary Education, J. Voogt and G. Knezek, Eds., Springer US. p. 449460, 2008.

[14] R. Jamieson-Proctor, P.C. Burnett, G. Finger, and G. Watson, " Ict Integration and Teachers' Confidence in Using Ict for Teaching and Learning in Queensland State Schools," Australasian Journal of Educational Technology, vol. 22, no. 4, pp. 511-530, 2006.

[15] R. Sani, "Promoting Ict and Learning in Schools :[Main/Lifestyle Edition]", in New Straits Times, April 16. 2007.

[16] B. Cavas, P. Cavas, B. Karaoglan, and T. Kisla, "A Study on Science Teachers' Attitudes toward Information and Communication Technologies in Education," The Turkish Online Journal of Educational Technology, vol. 8, no. 2, pp. 21-31, 2009.

[17] G. Beauchamp, "Teacher Use of the Interactive Whiteboard in Primary Schools: Towards an Effective Transition Framework," Technology, Pedagogy and Education,, vol. 13, no. 3, pp. 327-348, 2004.

[18] E. Neyland, "Integrating Online Learning in Nsw Secondary Schools: Three Schools' Perspectives on Ict Adoption," Australasian Journal of Educational Technology, vol. 27, no. 1, pp. 152-173, 2011.

[19] T.A. Beggs. "Influences and Barriers to the Adoption of Instructional Technology," in Mid-South Instructional Technology Conference. Murfreesboro, TN, 2000.

[20] L.H. Stuart, A.M. Mills, and U. Remus, "School Leaders, Ict Competence and Championing Innovations," Computers \&amp; Education, vol. 53, no. 3, pp. 733-741, 2009.

[21] P. Hubber, G. Chittleborough, C. Campbell, W. Jobling, and R. Tytler, "Supporting Ict Based Pedagogies in Science in Rural School Settings " Australian Educational Computing, vol. 25, no. 2, pp. 12-16, 2010.

[22] S.M. Sait, K.M. Al-Tawil, S. Sanaullah, and M. Faheemuddin, "Impact of Internet Usage in Saudi Arabia: A Social Perspective," IJITWE, vol., 2006.

[23] D.N.A. Hayes, "Ict and Learning: Lessons from Australian Classrooms," Computers \& Education, vol. 49, pp. 385-395, 2007. 
[24] A.G. Almekhlafi, "Preservice and Inservice Teachers, Computer Use in the United Arab Emirates," College of Education, vol. 1, no. 21, pp. 1-34, 2004.

[25] D. Sime and M. Priestley, "Student Teachers' First Reflections on Information and Communications Technology and Classroom Learning: Implications for Initial Teacher Education," Journal of Computer Assisted Learning, vol. 21, no. 2, pp. 130-142, 2005.

[26] A.A. Oyaid, "Education Policy in Saudi Arabia and Its Relation to Secondary School Teachers' Ict Use, Perceptions, and Views of the Future of Ict in Education". 2009, University of Exeter.

[27] P. Giavrimis, S. Giossi, and A. Papastamatis, "Teachers' Attitudes Towards Training in Ict: A Critical Approach," Quality Assurance in Education, vol. 19, no. 3, pp. 283-296, 2011.

[28] V. Cartwright and M. Hammond, "'Fitting It In': A Study Exploring Ict Use in a Uk Primary School," Australasian Journal of Educational Technology, vol. 23, no. 3, pp. 390-407, 2007.
[29] M. Walia, E. Yu, M. Iskander, V. Kapila, and N. Kriftcher, "The Modern Science Lab: Integrating Technology into the Classroom Is the Solution," in Advances in Computer, Information, and Systems Sciences, and Engineering, K. Elleithy, et al., Eds., Springer Netherlands. p. 358-363, 2006.

[30] Noida (2011) Ict for Better Learning Outcomes. Digital Learning.

[31] P. Gannon-Leary, "Implementing an Ict Centre for School and Community," Curriculum Leadership, vol. 7, no. 20, 2009.

[32] J. Sánchez, Á. Salinas, and J. Harris, "Education with Ict in South Korea and Chile," International Journal of Educational Development, vol. 31, no. 2, pp. 126-148, 2011.

[33] J. Sánchez and A. Salinas, "Ict \& Learning in Chilean Schools: Lessons Learned," Computers \& Education, vol. 51, no. 4, pp. 1621-1633, 2008.

[34] S. Dutta, Charles El-Hage, K. Sabbagh, and P. Tarazi, "Challenges for Information and Communication Technology Development in the Arab World," in Arab World Competitiveness Report 2002-2003 p. 186-208, 2002. 